\title{
Application of Fault Tree Analysis for Shipboard Zonal Electrical Distribution System: Study Case of Redesign From Radial Topology
}

\author{
Danang Cahyagi ${ }^{a}, *$, Eddy Setyo Koenhardono ${ }^{b}$ and Mat Syaiin ${ }^{c}$ \\ Institut Teknologi Sepuluh Nopember \\ Department of Marine Engineering \\ a.cahyagi16@mhs.ne.its.ac.id,b.eddy-koen@its.ac.id,c.matt.syaiin@gmail.com \\ *corresponding author
}

Keywords: Shipboard Power System, Marine Electrical, Risk Evaluation, Zonal Electrical Distribution, Safety.

Abstract:Zonal electrical distribution system (ZED) is an electric distribution system introduced by the navy. ZEDS is designed on having starboard and port dc busses supplied electrical zonal load. If a failure occurs on one distribution-line, it will be covered by another line. The whole designs and scenarios make the electrical system more reliable. In general, increasing reliability make the investment value tend to be higher. Therefore, this paper is present to provide an investment and risk perspective on the application of ZEDS. Existing shipboard power systems with radial topology is redesigned with ZEDS, and then both are evaluated. The investment and risk evaluation from using Radial and ZEDS is presented as results.

\section{Introduction}

In order to maintain continuity of power during operation, the power distribution system on board continues to develop. One way to make it happen is by applying zonal topology [1] [2]. Currently zonal system is a topology of electricity distribution which became one of the research subjects [3] [4]. In distributing power, the zonal topology uses two main buses where they are connected to the load zone, so that one load zone can be activated through two independent networks [5] [6]. In addition to increased power continuity, the use of zonal topology can also lower the cost of material distribution, and installation costs on the same ship. The decline in electricity costs is due to the management of zoning empowerment can effectively optimize the use of cables, and the busbar panel [7].

On the other hand, any changes or additions to system planning require mathematical approach to make sure the system is better. One of the commonly used parameters is the reliability parameter [8]. Therefore, this paper aims to find out how far the increase in reliability value of the ship's electrical distribution system due to the use of zonal distribution. 


\section{Literature Review}

\subsection{Zonal Electrical Distribution System}

In general, the ship uses a radial distribution system in supplying power at each load. This system uses the main panel as the power pool of the generator. Through the main busbar, power is supplied to each load. Generators on ships are generally operated parallel to the needs of the ship's electric during operation. Commonly used voltage is low voltage $380 \mathrm{~V}$ or $450 \mathrm{~Hz}$ with frequency $50 \mathrm{~Hz}$ or $60 \mathrm{~Hz}$. The voltage used will follow the working voltage of the electrical equipment. On boats with radial systems, in addition to using MSB, the ship system also uses an Emergency Switch board (ESB) to connect emergency generator generators to some vital equipment. In some ships, high voltage systems have also begun to be used to streamline cable usage [9] [10].

The idea of using a zonal distribution system comes from systems that have been applied to warships [11] . In an era of warfare, the US Department of Defense through its navy, trying to research in order to achieve cost effectiveness, but able to maintain the continuity of power. This is to realize productivity, resilience, and maximize survivability in war equipment during ship operations [7] [12]. With research by the US, it is expected that the size and weight of the system can be minimized so that the amount of ammunition and fuel that can be increased.

The use of the zonal distribution system is slowly being studied and projected to be used as a future ship distribution system [13]. This is supported by several studies showing that the zonal distribution system offers cost-saving construction, while offering continuity, and the flexibility of power usage [7] [14] [15]. The continuity of power usage will have an impact on the ship's operating pattern, since the mission carried by the ship depending on the operation of the equipment on board.

\subsection{Risk in power system}

Failure of power distribution system at one particular facility will cause blackout condition. This condition will have far-reaching impacts not only on revenue losses for generator owners and consumers, but also indirectly impacting communities and the environment [16] [17]. Therefore, the risk assessment of power system becomes a parameter like an electrical system.

A power system is generally evaluated quantitatively. Qualitative evaluation aims to create indicators that are capable of representing the actual system. An assessment is usually in harmony with improvement, or system change. To compare between the existing system, and the new system, the two systems are evaluated and then compared against each other. The comparison is made at the design stage prior to the decision making process.

Risk assessment of electric power systems may comprise several scope of empowerment systems. The qualitative evaluation of reliability in the generation, transmission, and distribution systems is one of the spare spaces. While other analysis that can be done is probabilistic criteria in system planning and operation, equipment aging failure management, and others. Each risk assessment scope of the empowerment system has the same important priority. The analysis undertaken at a facility will be based on the applicable regulations, and the parameters to be known.

The power system has three subsystems consisting of generation systems, transmission systems, and distribution systems. Each subsystem consists of many components consisting of generators, cables, busbars, panels, switches, transformers, and some enhancements. Each of these components has their respective failure chances called component failure probability. Each component when compiled into a system, then the probability of failure probability will be referred to as a chance of system failure. Any failure can be classified as independent, and dependent. 
The second part of the risk assessment process on electrical power systems is to select a system failure state, and calculate the reliability value. There are two types of methods in choosing a system state that is state enumeration, and Monte Carlo simulation. Each method has advantages and challenges. Generally, state enumeration is more efficiently used in simple arranged systems. However, in more complex systems, Monte Carlo simulation is preferred.

In the third stage analysis, the value of system reliability that has been calculated in the second stage analysis then further analysis to know the consequences of system changes. Based on the electrical power system, the possible analyzes are the balance of power analysis, or the identification of the system conFigureuration, or other electrical power system analysis.

\section{Research Method}

\subsection{Fault Tree Analysis}

Fault tree analysis is a common standard used to determine the reliability and safety value of system changes. In its development, fault tree analysis has been used in many industries, such as food, textile, chemical, computer, software, transportation, and electrical industries. Fault tree analysis is widely accepted as part of the probabilisitic safety assessment in terms of increasing reliability values in nuclear power systems, and space missions.

As one of the analytical methods, fault tree analysis is an analysis of combining graphs and logic which is then referred to as the fault tree or fault tree model. Fault tree analysis can be done with qualitative, or quantitative, and can use component failure data in the calculation process. Each component can be represented as a basic event that can be scenarized against other components. The total relationship between each basic event will represent the value of the system failure which will be called the top event.

However, fault tree analysis does not model the failure of all components. The scope of the fault tree analysis only models failure through its failure mode which can cause system failure.

Fault tree analysis can be done by following the following procedure [18]:

- Determine the object system to be analyzed

- Determine the top event of the system operation

- Determine the scope, and the basic rules in the system analysis

- Creating a fault tree chart

- Evaluate the fault tree qualitatively

- Prepare probabilistic failure database and its relationship with basic event

- Evaluate the fault tree qualitatively

- Bring out the results that have been obtained from the analysis process

Calculation of failure probability is a basic calculation of fault tree analysis. Generally the component failure occurs at a constant failure rate $\lambda$ In the simple case, the probability of failure depends on the failure rate $\lambda$ and the time $t$ as shown in equation 1 .

$$
\mathrm{P}=1-\mathrm{e}-\lambda \mathrm{t}
$$

Where $\lambda$ is the rate of failure, and $t$ is time.

Probability for component failures that have been obtained then further analysis based on the gate fault setting scenario. An AND gate represents the component where a system failure can occur if both components fail simultaneously. This component failure mode scenario can be represented as intersection with the following calculations (2) 


$$
\mathrm{P}(\mathrm{A} \text { and } \mathrm{B})=\mathrm{P}(\mathrm{A} \cap \mathrm{B})=\mathrm{P}(\mathrm{A}) . \mathrm{P}(\mathrm{B})
$$

An OR gate represents a component where a system failure can occur if one component fails. This failure scenario can be represented as a union with the following (3).

$$
\mathrm{P}(\mathrm{A} \text { or } \mathrm{B})=\mathrm{P}(\mathrm{A} \cup \mathrm{B})=\mathrm{P}(\mathrm{A})+\mathrm{P}(\mathrm{B})-\mathrm{P}(\mathrm{A} \cap \mathrm{B})
$$

Since the probability of failure in the fault tree tends to be small (more than 0.01), then $\mathrm{P}$ (A $\cap$ B) is generally considered to have a small error value, and the output of OR gate is assumed to be mutually exculsive occurrence.

$$
\begin{array}{r}
\mathrm{P}(\mathrm{A} \text { or } \mathrm{B}) \approx \mathrm{P}(\mathrm{A})+\mathrm{P}(\mathrm{B}), \mathrm{P}(\mathrm{A} \cap \mathrm{B}) \approx \\
0=1-(1-\mathrm{P} 1) \cdot(1-\mathrm{P} 2)
\end{array}
$$

\subsection{Fault tree analysis for zonal distribution}

In this paper, the process of fault tree analysis evaluation on ship distribution system is done on radial system, and zonal system. Both systems are arranged according to actual ship specifications. The evaluated radial system represents the currently commonly used system, and the zonal system is an improvement that is currently being developed. This paper will only cover reliability improvement indicators. Both electrical distribution systems are evaluated, and compared against each other.

Radial system consists of generator, main switch board, cable, and load. The power distribution process on the radial system starts from the generator that is connected to the main switch board. The main switch board will be the connecting medium between the plant and the load. The generator parallelization process is also done through the main switch board. Power from the main switch board is then channeled at each load.

The zonal system consists of generators, two main busbars (portside bus, and starboard bus), load zones, and cables. The generator will be supplied via portside bus and an independently connected starboard bus. The power from portside bus and starboard bus is then channeled to each of the load zone panels, and forwarded to the electrical components. One load zone can be supplied from portside bus or starboard bus. Figure. 1 shows the power distribution topology with Radial Distribution System.

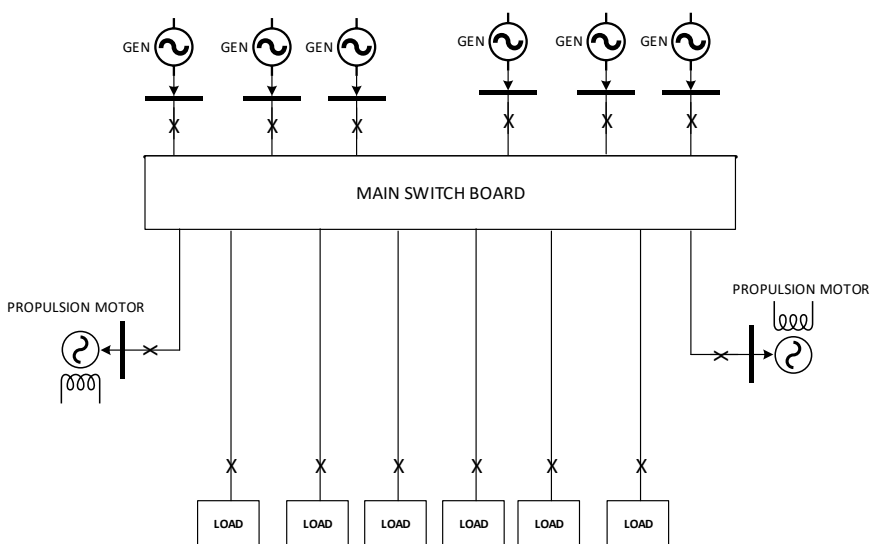

Figure. 1: Example of radial distribution system topology

The second stage of the analysis is to determine the top event of the electrical distribution system operation. In this paper, the value of failure that is used as top event is not channeled power 
on the load. Unavailability of power in the load may occur if certain components of the distribution network fail.

The next step is to make the basic rules related to the relationships between components that will form the system, describe it in a fault tree chart, and evaluate it qualitatively. Figure. 3 shows the fault tree construction for radial distribution system. Figure. 2 shows the power distribution topology with Zonal Distribution system.

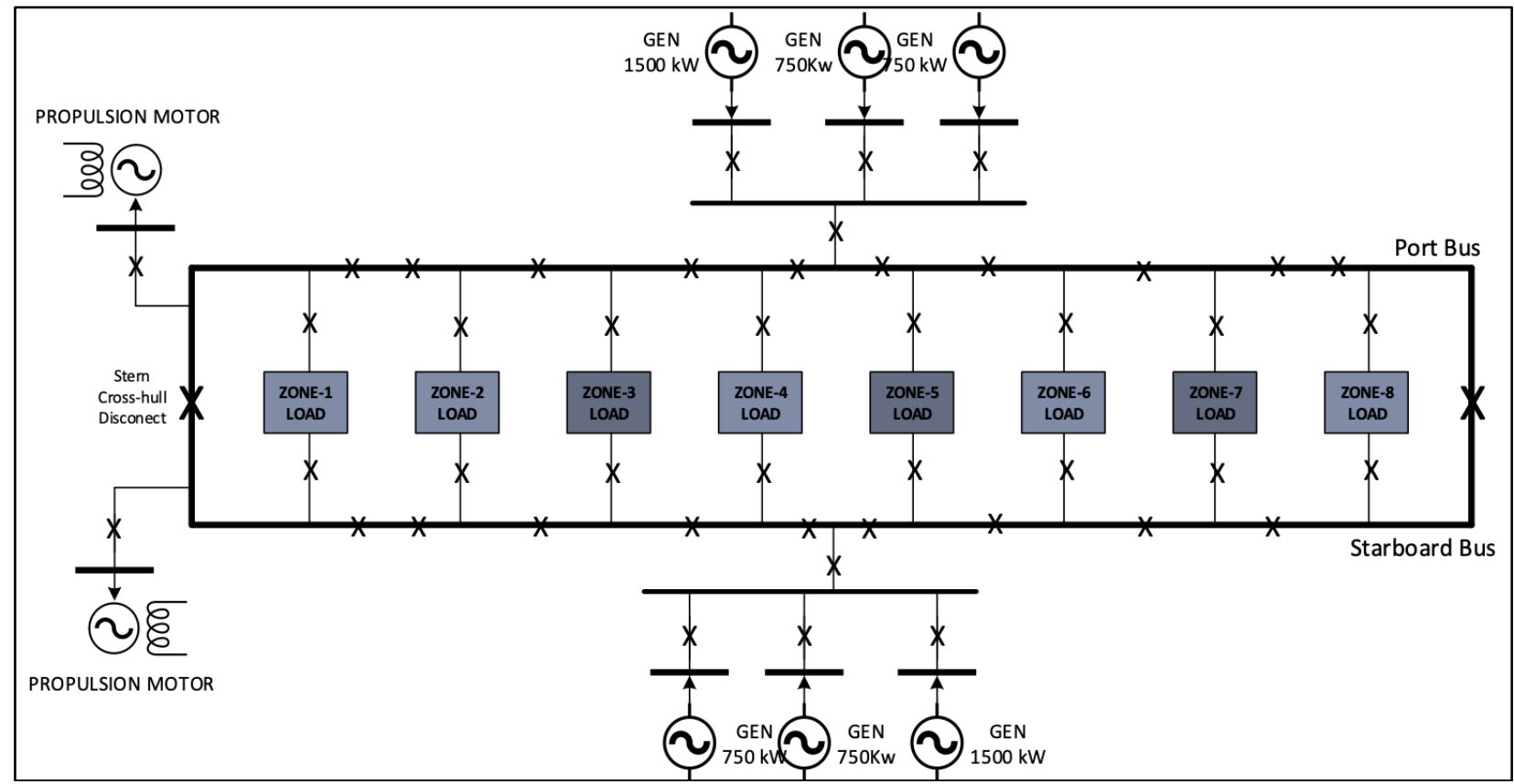

Figure 2: Example of zonal distribution system topology

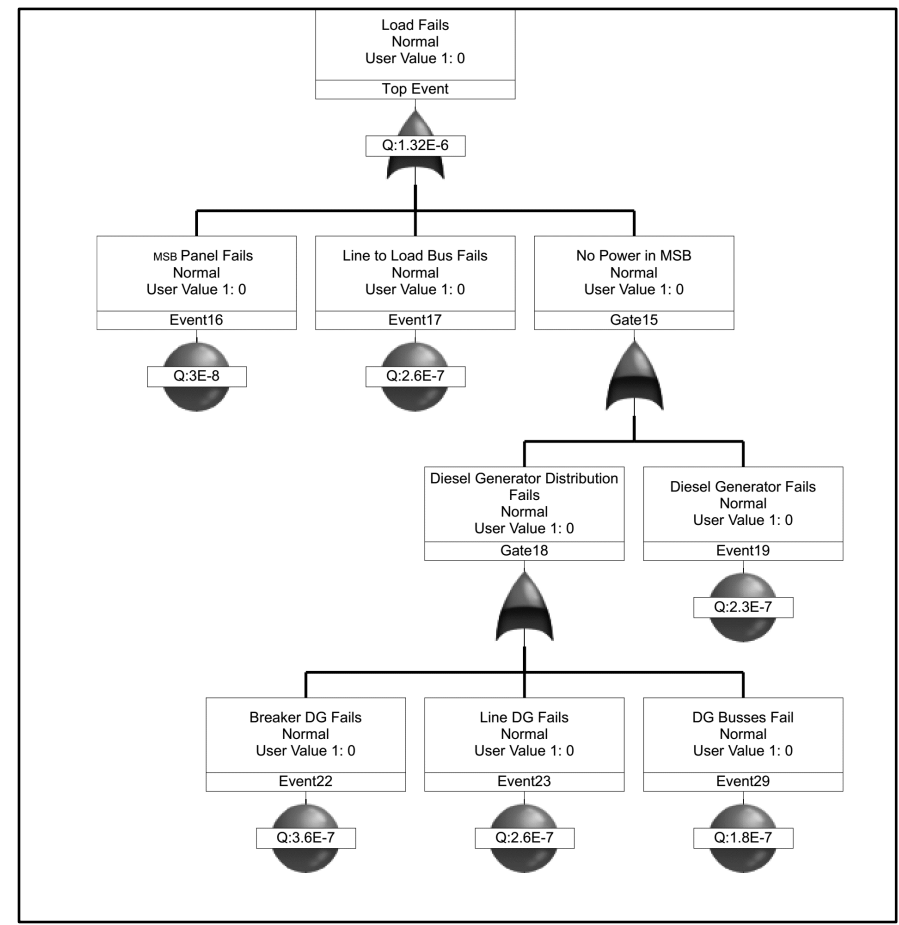

Figure 3: Fault tree construction for radial distribution system 
Figure. 4 shows the fault tree construction for zonal distribution system.In order to analyze the fault tree quantitatively, data on the probability of component failure needs to be collected. The probability of component failure data can be obtained through direct system observation, or through a data bank that can represent a system failure index.

Generally any bank data is the result of research that has been done for many years. The research is concerned with observing the failure of each component. It is expected that the bank data can have a certain component failure data when no data history of component failure on the system being analyzed.

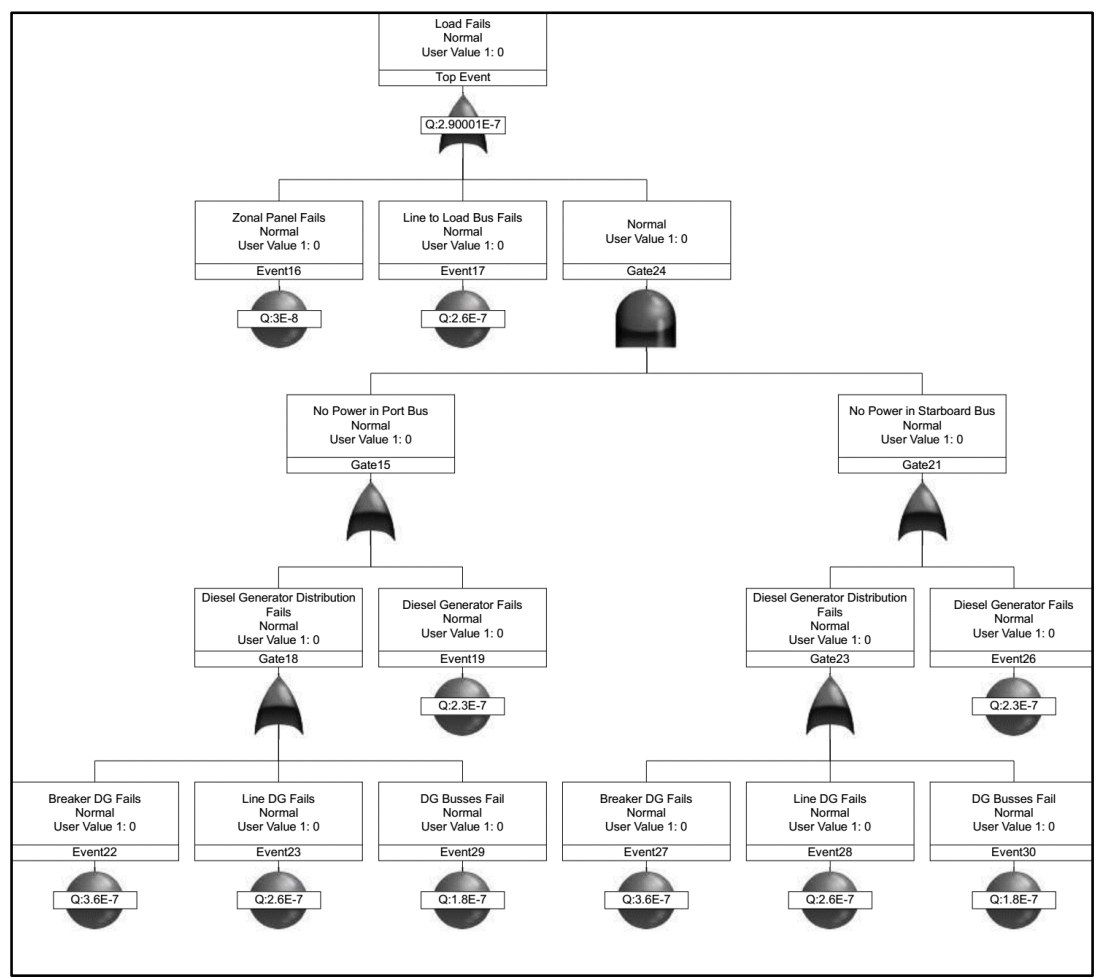

Figure 4: Fault tree construction for zonal distribution system.

Table 1 shows the failure probability index of the ship's electrical system. The data is taken from the International atomic energy agency and OREDA (The Offshore and Onshore Reliability Data). From the table it can be seen that the greatest chance of failure is in the breaker, while the lowest chance of failure is panel failure.

Table 1: The Components Failure Probability Index

\begin{tabular}{lll}
\hline No. & Component & Failure Probability $\left(\mathbf{1 0}^{-\mathbf{7}}\right)$ \\
\hline 1 & Panel fails & $0.3^{*}$ \\
2 & Line to load fails & $2.6^{*}$ \\
3 & Diesel generator fails & $2.3^{* *}$ \\
4 & Breaker fails & $3.6^{*}$ \\
5 & Line form generator fails & $2.6^{*}$ \\
6 & Diesel busses fail & $1.8^{*}$ \\
\hline$*$ ) International atomic energy agency, 1988
\end{tabular}




\section{Result}

\subsection{Radial system risk evaluation result}

In the supply-to-load process, radial systems use the power supply of the Main Switch Board (MSB) unit. Therefore, the probability of distribution system failure will occur if the failure of MSB, network to load, or no power supplied in MSB. The absence of power on the MSB can be reduced to a failure of the generator distribution system, or failure arising from the generator itself. The failure pattern of the exisiting system can be simplified through the FTA shown in Figure. 4. With FTA analysis, the value of existing distribution system failure is 1.32 x 10-6.

\subsection{Zonal system risk evaluation result}

In a zonal distribution system, a single load zone unit allows to be supplied from both the portbus and the starboard bus. Therefore, one load zone unit can be said to fail when the two main buses fail, or the distribution system fails on the load zone itself. With this failure scenario, the system failure rate will be $2.9 \times 10-7$, or four times better than the existing system.

Table 2 presents an evaluation of the probability of system failure values between radial and zonal systems.

Table 2: The Components Failure Probability Index

\begin{tabular}{lll}
\hline No. & Topology & Failure Probability $\left.\mathbf{( 1 0}^{-\mathbf{7}}\right)$ \\
\hline 1 & Radial Distribution System & 13,2 \\
2 & Zonal Distribution System & 2,9 \\
\hline
\end{tabular}

\section{Conclusion}

Implementation of zonal distribution system as shipboard power system may increase the power continuity as one load zone can be activated from two main bus bus (portside bus and starboard bus). To find out the indicator of reliability of electrical distribution system quantitatively, fault tree analysis can be used as an anisal method. The process of fault tree work on the electrical distribution system begins with determining the system to be evaluated, determining the top event of system failure, and calculating the result based on available data. Benefits derived from the application of the zonation system in this study is the quality of electrical distribution system becomes better index by the value of system failure which Radial System has a value of $\mathrm{Q}=1.32 \mathrm{x}$ $10-6$ to $\mathrm{Q}=2.9 \times 10-7$ in zonal distribution.

\section{References}

[1] J. Momoh, S. Kaddah and W. Salawu, "Security assessment of DC zonal naval-ship power system," Canada, 2001.

[2] LCE, "NAVSSES Upgrades Machinery Control System, Brings Navy One Step Closer to First All-Electric Warship," 2014. [Online]. Available: https://www.lce.com/pdfs/NAVSSES-Upgrades-Machinery-Control-SystemBrings-Navy-One-Step-Closer-to-First-AllElectric-Warship-327.pdf. [Accessed 20 July 2017].

[3] C.-L. Su and C.-T. Yeh, "Probabilistic Security Analysis of Shipboard DC Zonal Electrical Distribution Systems," Power and Energy Society General Meeting - Conversion and Delivery of Electrical Energy in the 21st Century, 2008 IEEE, pp. 1-7, 2008.

[4] M. Baran and N. Mahajan, "DC distribution for industrial systems: opportunities and challenges," IEEE Transactions on Industry Applications, vol. 39, pp. 1596-1601, 2013.

[5] W. Zhu, S. Pekarek, J. Jatskevich, O. Wasynczuk and D. Delisle, "A Model-in-the-Loop Interface to Emulate Source Dynamics in a Zonal DC Distribution System," IEEE TRANSACTIONS ON POWER ELECTRONICS, VOL. 20, NO. 2, pp. 438-445, 2005. 
[6] A. Dubey and S. Santoso, "A two-level topology design framework for reliable shipboard power systems," Invention, vol. 1, pp. 1-19, 2016.

[7] J. G. Ciezki and R. W. Ashton, "Selection and Stability Issues Associated with a Navy Shipboard DC Zonal Electric Distribution System," IEEE Transcation on Power Delivery, vol. 15, no. 2, pp. 665-669, 2000.

[8] R. Laskowski, "Fault Tree Analysis as a tool for modelling the marine main engine reliability structure," Scientific Journals of the Maritime University of Szczecin, pp. 71-77, 2015.

[9] M. R. Patel, Shipboard Power System, US: CRC Press, 2012.

[10] A. Emadi, M. Ehsani and J. M. Miller, Vehicular Electric Power Systems: Land, Sea, Air, and Space Vehicles, New York: Marcel Dekker, 2004.

[11] M. Elshaer, A. Mohamed and O. A. Mohammed, "Integration of Sustainable Energy Sources into DC Zonal Electric Distribution Systems," Power and Energy Society General Meeting, 2011 IEEE, pp. 1-7, 2011.

[12] J. Mindykowski, "Case Study-Based Overview of Some Contemporary Challenges to Power Quality in Ship Systems," Invention, vol. 1, pp. 1-30, 2016.

[13] C. R. Petry and J. W. Rumburg, "Zonal Electrical distribution system: An affordable architecture for the future," Naval Engineeri Journal 105 (3), pp. 45-51, 2009.

[14] C. N. Tidd, Hardware model of a shipboard Zonal Electrical Distribution System (ZEDS) Alternating Current/Direct Current (AC/DC), California: Institutional Archive of The Naval Postgraduate School, 2010.

[15] S. Wu, L. Xia, C. Zhang, X. Wang and C. Li, "Electric propulsion effects on DC Zonal Electrical Distribution system stability," Modelling, Identification \& Control (ICMIC), pp. 144-149, 2012.

[16] W. Li, Risk Assessment of Power Systems, Canada: the Institute of Electrical and Electronics Engineers, Inc., 2005.

[17] T. Chen, M. Chen, K. Hwang and E. Chebli, "Distribution system power flow analysis-A rigid approach," IEEE Trans. Delivery, vol. 6, p. 1146-1152, 1991.

[18] M. Cepin, Assessment of Power System Reliability, London: Springer, 2011. 